\title{
Aspiring to higher education in regional and remote Australia: the diverse emotional and material realities shaping young people's futures
}

\author{
Skye Gibson ${ }^{1,2}(\mathbb{D}) \cdot$ Sally Patfield ${ }^{1,2}$ (D) Jennifer M. Gore ${ }^{1,2}$ (D) Leanne Fray ${ }^{1,3}$ (D)
}

Received: 22 July 2020 / Accepted: 28 June 2021 / Published online: 28 July 2021

(c) The Author(s) 2021

\begin{abstract}
Students from regional and remote areas remain significantly under-represented in higher education despite decades of equity policy designed to encourage participation. One explanation is that policy initiatives often overlook the realities in local rural contexts that can make higher education less desirable. Applying the theoretical lens of 'doxic' and 'habituated' aspirations, this paper analyzes interviews with 13 students, 10 parents/carers, and 4 teachers from one regional and one remote community in NSW, Australia. We document the emotional and material realities shaping young people's imagined futures in these communities, highlighting the commitment to a rural lifestyle in one, and the desire to escape the other community in decline. We argue that developing successful initiatives to address equitable participation in higher education requires a departure from hegemonic discourses of 'rurality' and greater recognition of and respect for the diverse needs and desires of regional and remote students.
\end{abstract}

Keywords Higher education $\cdot$ Aspirations $\cdot$ Rural $\cdot$ Regional $\cdot$ Remote $\cdot$ Realities

Skye Gibson

skye.gibson@newcastle.edu.au

Sally Patfield

sally.patfield@newcastle.edu.au

Jennifer M. Gore

jenny.gore@newcastle.edu.au

Leanne Fray

leanne.fray@newcastle.edu.au

1 Teachers and Teaching Research Centre, School of Education, University of Newcastle, Callaghan 2308, Australia

2 The University of Newcastle, Hunter Building HA89, University Drive, Callaghan, NSW 2308, Australia

3 The University of Newcastle, Hunter Building HA101, University Drive, Callaghan, NSW 2308, Australia 


\section{Introduction}

Despite decades of policy initiatives aimed at improving access to higher education, people living in regional and remote Australia continue to be significantly under-represented in university (Cardak et al., 2017; Committee for Economic Development of Australia [CEDA], 2018; Halsey, 2017, 2018). Even after the introduction of the demand-driven funding system by the Federal Government which lifted the 'cap' on undergraduate enrolments, there have been no significant gains in participation rates for this group (Burnheim \& Harvey, 2016; National Centre for Student Equity in Higher Education [NCSEHE], 2017). Reasons for this longstanding under-representation are complex and multifaceted, including a broad range of socio-cultural, geographic, and economic conditions (Abbott-Chapman, 2011; NCSEHE, 2017), as well as academic achievement, school completion rates, and available post-school opportunities (Halsey, 2018a). Educational inequalities are also more subtly manifest in compound forms of disadvantage, particularly through the intersection of rurality with class, race, and gender (Bradley et al., 2008; CEDA, 2018).

In light of relatively stagnant enrolment patterns, the Federal Government has sought to 'widen participation' not only by expanding the higher education sector but also by increasing diversity. In the process, social justice and economic goals have become closely entwined (Rizvi \& Lingard, 2011), driven by the notion that a society that is ostensibly equitable is also of benefit to the country's economic capacity (NCSEHE, 2017; CEDA, 2018). In practice, however, social justice outcomes have taken second stage to the economic goal of increasing human capital in the 'global knowledge economy' (Abbott-Chapman, 2011), resulting in a somewhat narrow focus on quantitative gains in university enrolments (Whitty \& Clement, 2015). Indeed, some commentators argue that the widening participation discourse has contributed to the 'problem' by conveying the assumption that university is the best pathway for all, thus, delegitimising other kinds of aspirations (Gale, 2015).

\section{What is the 'problem' for rural communities?}

While overall rates of higher education participation among Australians have increased (Norton et al., 2018), students from regional and remote areas are less than half as likely as those from metropolitan areas to attain a university qualification (NCSEHE, 2017). If proportional university participation is a key indicator of success, then clearly higher education equity policy has yet to achieve real impact for this equity group.

Improving educational outcomes for regional and remote students is fundamentally connected with the effects of globalisation in rural areas (Pini et al., 2015), including youth out-migration (Corbett \& Forsey, 2017), mechanisation of the agricultural industry (Alston \& Kent, 2009; Gray \& Lawrence, 2001; Halsey, 
2017), and reduced employment due to the closure of key services (Gray \& Lawrence, 2001; Halsey, 2018a). These changes have resulted in the dramatic decline of many rural communities in Australia (Alston \& Kent, 2009; Dufty-Jones \& Connell, 2014; Farrugia et al., 2014; Gray \& Lawrence, 2001). Although major shifts in production have affected employment in agricultural industries since at least the 1950s (Alston \& Kent, 2009), the loss of employment opportunities in affected communities has been accentuated in recent years by environmental conditions such as severe drought (Alston \& Kent, 2009; Edwards et al., 2018). There is no doubt that post-school opportunities for students in many regional and remote areas have been negatively impacted and restricted by these changes.

Unlike many rural communities in other parts of the world, rural Australia is geographically diverse, very remote, and sparsely populated, (Alloway et al., 2004; Alloway \& Dalley-Trim, 2009; Beutel et al., 2011). Populations are distributed across a broad range of landscape types-from deserts to tropical coasts. However, diversity is not limited to geography alone. There is enormous diversity in economic status, access to facilities and services, educational attainment, occupational engagement, social values, and attitudes, as well as aspirations and expectations (DalleyTrim \& Alloway, 2010). Collectively, the rural social space can be viewed as "richly complex and contradictory" (Reid et al., 2010, p. 267) with extremes of diversity within and between rural communities (Pini et al., 2016; Reid et al., 2010).

It is well understood that the metropolitan 'template' for education and educational pathways is not necessarily appropriate for regional and remote contexts (Guenther et al., 2014; Roberts \& Green, 2013; Reid et al., 2010). We argue it is equally important to recognise the significant diversity within and between regional and remote locations. Each locality, and the region to which it belongs, are impacted by changes and the conditions that drive and shape those changes to varying degrees. Therefore, any broad-brush approach to addressing equity in regional areas will be limited (NCSEHE, 2017) if the 'rural' is treated as a fixed and homogeneous entity (Bryant \& Pini, 2011; Pini \& Mayes, 2015; Pini et al., 2010; Pini \& Mills, 2015; Reid et al., 2010). Understanding the wide diversity of regional and remote contexts has been critical to sustaining improvements to schools in rural areas (Halsey, 2018a). Surely, the same approach must apply to the widening participation agenda in higher education.

To explore and make visible this diversity, our paper examines how rurality is experienced by residents in two different communities in New South Wales, Australia, which impacts young people's post-school aspirations in vastly different ways. Our stance departs from hegemonic discourses that treat rurality as a homogeneous category, recognising an urgent need to understand the complex and diverse realities that influence the aspirations of young people from regional and remote areas (NCSEHE, 2017). Indeed, the widening participation agenda-however, well intentioned in terms of social justice-continues to oversimplify rurality, therefore, failing to improve outcomes for regional and remote Australians. Our paper seeks to provide greater clarity about young people's actual desires and needs in regional and remote Australia and, therefore, generate a more nuanced understanding of how best to support their access to post-secondary educational pathways. 


\section{Doxic and habituated logics of aspiring to higher education}

Complementing the Australian government's agenda to 'widen participation' in higher education, a wealth of literature examining the aspirations of young people has emerged over the last 10 years. Researchers have examined: the capacity to aspire to higher education (Bok, 2010; Smith, 2011); aspirations for higher education of students from low-SES circumstances (Gale \& Parker, 2015); the impact of SES on student aspirations (Gore, Holmes, Smith, Southgate et al., 2015a); student aspirations for careers requiring a university education (Gore et al., 2017); and equity and student mobility (Sellar et al., 2011).

Of particular importance to the focus of this paper, the aspirations of rural youth have been studied extensively, including: mobility and educational discourse and practice (Corbett \& Forsey, 2017); the role of social and cultural capital in post-school aspirations (Cuervo et al., 2019; Kilpatrick \& Abbott-Chapman, 2002); key influences on aspirations for higher education (Fray et al., 2020); and how outreach initiatives can support aspirations for higher education (Gore, Holmes, Smith, Lyell et al., 2015b; Kilpatrick et al., 2019).

However, much of this work is based on the premise that higher education represents the end goal of young people's post-school desires. As a counterpoint to this research, we take a different view, using the lens of doxic and habituated aspirations (Zipin et al., 2015) to examine the emotional and material realities of life in regional and remote Australia, which, in turn, shape young people's interest in diverse postschool futures. Arguably, the widening participation agenda is grounded in a doxic logic, which equates a better education with a better job and therefore a better life. But how does this logic translate to life in regional and remote Australia, given everchanging conditions and the immense diversity within and across communities?

This lens is particularly useful for our research given the links between Bourdieu's (1992) conceptualisation of doxa and habitus and the process of aspiration formation (Zipin et al., 2015). In this context, doxa refers to the core logics that are commonly accepted as the ideals of everyday life, subsequently shaping actions and the perceived limits of what is possible. Habitus pertains to an individual's deeply embodied set of dispositions toward the world that develop as a consequence of both history and lived experience within the conditions of a given socio-cultural and material position (Bourdieu, 1990). Put simply, in relation to aspirations, a doxic logic refers to what is idealistic, while a habituated logic addresses what is realistic (Huijsmans et al., 2021; Nygård, 2017).

In the current context of higher education policy, a doxic logic for aspiring to university foregrounds self-advancement or upward mobility through education. It does not recognise other, arguably legitimate, aspirations (Gale, 2015) that do not require a university education. By aligning more closely with the government's economic goals for increasing human capital than with its social justice goals, the doxic logic that underpins the widening participation agenda risks misrecognising the aspirations held by many young people in regional and remote locations.

Habituated aspirations, by contrast, are formed through the embodiment of dispositions and are represented by a deeply internalised sense of what is possible 
within the socio-cultural context (Zipin et al., 2015). Habituated aspirations tend to be practical and encompass ideas about the future that are visible and viable. Choice is limited by the opportunities and constraints of an individual's circumstances. This is particularly relevant to young people in regional and remote locations who typically cannot access the same set of choices in their communities afforded to young people from metropolitan areas. Moreover, altered or downsized traditional labour markets have fractured intergenerational legacies, such as the family farm, seasonal harvesting, or the local general store, and further limit available options for future employment.

Applying Zipin et al.'s (2015) conceptual elaboration of doxic and habituated logics, this paper presents two case studies which explore the salience of the widening participation agenda for students from regional and remote communities. We tease out how these logics interact with the emotional and material realities of young people's lives to shape their aspirations. In so doing, we aim to uncover some of the shortcomings in current higher education policy that aims to alleviate under-representation.

\section{Methods}

Our analysis draws on data collected for a larger project that investigated the educational and occupational aspirations of students in Years 3-12 (aged approximately 8-18 years) enrolled in government schools in the state of New South Wales, Australia. The larger, mixed-method study involved two components: (1) online surveys completed by 1463 students, 57 parents/carers, and 130 teachers in 33 government schools situated in regional, remote, and very remote areas of the state; and (2) focus groups and interviews conducted with 144 students, 46 parents/carers, and 49 teachers/principals in a sub-sample of 26 schools. Schools were purposively recruited to the study for their geographic profile and categorised as Inner Regional, Outer Regional, Remote or Very Remote according to the Australian Statistical Geography (ASGS) Remoteness Structure as developed by the Australian Bureau of Statistics $\left(\mathrm{ABS}^{1}\right)$, which measures and classes remoteness according to relative access to services. For the current paper, we draw on data from the qualitative strand only in order to explore perspectives across locations.

The interviews and focus groups centred on the following broad topics, with slightly different questions for each participant group: perceptions of the community; schooling; post-school aspirations; careers activities within schools; and family experiences with higher education and/or vocational education. All student interviews and focus groups were held on school grounds during normal school hours, while interviews with parents/carers and teachers were either held at school or via phone. All interviews and focus groups were digitally audio recorded, with each location and school allocated a pseudonym to protect anonymity. Students were allocated a pseudonym if they did not choose their own.

\footnotetext{
1 See https://www.abs.gov.au/websitedbs/D3310114.nsf/home/remoteness+structure.
} 
For this paper, we present two case studies that represent diverse geographic locations: Oldfields, Outer Regional; and Tomatillo, Remote. Using a theoretically informed deductive approach to analysis (Creswell, 2013) and a rural standpoint (Roberts, 2014), which "actively privileges rural outlooks" (Howley \& Howley, 2014, p. 35), focus group and interview transcripts were coded using the NVivo 11 software programme. Framed by the lens of doxic and habituated logics, our analytical approach focused on how school students articulated their aspirations, supplemented by the ways in which significant adults constructed the imagined futures of young people in these same communities. Our aim was to examine diversity not only among the communities themselves, but also in the ways that educational trajectories are conceived and spoken about.

It is important to acknowledge that our account of these two diverse locations is necessarily shaped by those who agreed to participate and the stories they chose to tell. There are no doubt other perspectives that we were not privy to in this study.

The study was approved by the University of Newcastle's Human Research Ethics Committee (H-2012-0276) and the NSW Department of Education (SERAP 2012188).

\section{Oldfields: rural connection, local aspirations}

Oldfields is a regional community with a population of $<2000$ residents, of whom approximately 5\% identify as Indigenous. Residents describe Oldfields in positive terms such as "close-knit", "supportive", and "peaceful". There are "heaps of friendly people" who "will help out if things seem to go wrong". Residents enjoy the lifestyle it provides. It is a hardworking community with many farming families in the area. There is plenty to do recreationally, with an abundance of sporting clubs and popular horse-related activities, which local youth enjoy. With limited shops, locals travel out of town if they want more than the basics.

One of the teachers, Lars, explains that traditionally the community has been fairly "stable", but that more recently there has been an influx of people from "out of area". Iola, another teacher, suggests that the newcomers are mostly people coming for "family ties". While this has been "good in a way", it has also resulted in some "less positive experiences". Lars explains that while some of the newer residents have come to the area to take up professional work, others may be taking advantage of the lack of public transport, which means they can claim benefits without needing to look for work. Our other participants, however, did not make reference to any tensions, instead describing a harmonious and supportive community.

The main industries in and around Oldfields are agriculture, construction, and mining, with thriving employment opportunities in these fields. The school and local farms have traditionally been the main employers in town, but there has been a shift in the way farms operate. As more sophisticated machinery and/or foreign investors take over the farms, there is less need for farmworkers. While there is still interest in working with animals and farming among some young people, others are choosing careers in building and construction and are taking up traineeships prior to finishing school. 
We interviewed seven students, three parent/carers, and two teachers at Oldfields Central School (OCS), a combined primary and secondary school, which is also the only government school in the township. The school has almost 300 students, $25 \%$ of whom are Indigenous. The high proportion of Indigenous students at the school compared to the much smaller percentage within the general population might be explained by some wealthier families in Oldfields sending their children to private schools outside the community.

While Lars explains that around $20 \%$ of the young people go to university, the community is one in which most young people value their rural lifestyle and make choices based on a desire to stay. For many students, there are alternatives to higher education that provide them with appropriate, practical, and desirable pathways into thriving local industries:

[My son, Randall, Year 12] has actually already been offered one [job]. ... Yes, he's into horse riding and mustering cattle and that kind of thing and he does want to do something on the land. ... I think he has the option... to go to Tocal $^{2}$ when he's finished school. ... If he goes to Tocal for a year after school, he comes out with the equivalent that he's been to uni for four years. (Tania, parent)

While the idealism of doxic logic is not expressed through an aspiration to pursue a university education, students like Randall seek the benefits of education appropriate to their chosen pathway. Rather than university being positioned as the marker of success (NCSEHE, 2017), Randall is intent on developing skills relevant to his interests ("something on the land").

Emil, a Year 12 student at the school, mentioned his girlfriend lives in a regional town roughly 1.5 h' drive away. He plans to move there to study at the local Technical and Further Education institute (TAFE) and then work in the nearby mines:

I have family that work in the mines and people that I work for now, my boss's wife, her father is a head supervisor in the mines, and I'd get a job through them. A lot of my uncles and relatives work in the mines. ...I've always liked doing that sort of stuff like driving machinery. (Emil, Year 12 student)

Like Randall, Emil is keen to take up work that he enjoys ("I've always liked doing that sort of stuff") and to seek out the relevant educational pathway. Emil's mother is a schoolteacher, and his father works for the local land council. His father is keen for him to follow in his footsteps, but Emil is not interested in administrative work. Instead, he is choosing to connect with his extended family's history in the mining industry ("a lot of my uncles and relatives work in the mines"), and to rely on a connection ("I'd get a job through them"), highlighting the value of social networks in obtaining secure employment (Kilpatrick \& Abbott-Chapman, 2002).

Each of these aspirational stories can be viewed as habituated, in the sense that Randall and Emil are both realistic about what they would like to do and, to a

\footnotetext{
${ }^{2}$ Tocal Agricultural College provides specialised training in rural industries.
} 
degree, embody their desires through past family experiences. However, they are neither constrained nor held back by their circumstances (Cuervo \& Wyn, 2017) and, as such, demonstrate a degree of agency (Pini et al., 2016) or reflexivity (Farrugia et al., 2014) that removes the 'taken for granted' nature of habituated logic. In their own way, they are following their ideal pathway, which sits outside the hegemonic (doxic) ideal of upward mobility through university education. Randall and Emil both demonstrate a relationship to their locale that "is not a chain which limits [their] possibilities" (Farrugia et al., 2014, p. 1043) but exemplifies how rural youth can mobilise the resources and opportunities available to imagine their successful futures.

Previous research has shown that rural youth leave their communities primarily because of a shortage of educational and employment opportunities (Fray et al., 2019; Eacott \& Sonn, 2006). However, in Oldfields and the surrounding area, gainful employment in mining and on the land can be realised without leaving. Nonetheless, a broader range of occupational opportunities is limited in the local area. Young people interested in pursuing study or work in other industries must commute or move away. Students address this reality in practical, matter-of-fact terms:

I love being in Oldfields, even though it's so little and there's not much you can do. But then again, I want more opportunities for myself than what I can get here. ... Working in a bigger hospital I'd be able to do midwifery just as midwifery. But, if I want to come back here, I have to be a nurse as well ... because there's not enough births here to just be a midwife. I wasn't interested in being a nurse, I just want to do midwifery. (Heike, Year 11 student)

Certain material realities of rural life can stand in the way of students' aspirations. Heike illustrates the common desire among rural youth to return to their community to work. The swing between doxic and habituated aspirations is evident-("I want more opportunities for myself", "but, if I want to come back here"). The pursuit of higher education is compromised by limitations in the local area. Heike's primary aspiration to be a midwife will be thwarted if she returns to work in Oldfields, degree in hand. Subsequently, she indicates she will become a teacher instead.

This kind of 'swing' between doxic idealism and the material realities of life was also articulated by teachers from Oldfields in their description of students' aspirations:

Ideally, we want our kids to go beyond high school, whether that's TAFE, whether that's university, whether that's some form of college or whether it's the military ... Explore, explore. I'd like them to have a crack at anything, be brave enough to go, 'I want to pursue law', ... 'I want to be an architect' or whatever, rather than go, 'this is what my family have done', 'this is achievable', 'this is attainable'. (Lars, teacher)

At the same time, Lars recognises limitations: 
There's no transport from Oldfields to Odessa ${ }^{3}$ and Railton. ${ }^{4}$ Also, TAFE reduced a large number of courses, so that kind of killed a lot of [those options], which is a shame. University, the idea of living away from home can be a bit of a hindrance, particularly if they don't have family to rely on. (Lars, teacher)

Lars' language captures a doxic disposition towards students' futures ("ideally", "be brave enough") and he selects examples that fit well within the doxic realm of upward mobility ("law", "architecture"). The contrast with the material realities is stark ("no transport", "reduced TAFE", no "family to rely on") and paints a clear picture of how changing conditions in regional and remote Australia impact on the freedom to pursue aspirations for higher education (Robinson, 2012).

Darma, one of the parents interviewed, explains that she would "love all [her] kids to go through university to get an awesome education". From her perspective:

It's getting harder to live, everything's getting more expensive. So, if you do have a good job, then you get the money, and then you're able to live I suppose. I don't want to see them homeless by any means. So, if you get a good education, you get a good job, and then you can live well. (Darma, parent)

Darma aligns university education with a standard of living that her children might not otherwise achieve if they stay in Oldfields. Her logic is that a "good education" means a "good job", and therefore, the financial means to "live well", aligning closely to the upward mobility imperative of doxic aspirations. In many instances, this requires that education and work are taken up away from home and family, in one of the major centres. For example, Darma speaks about her 20-year-old daughter who goes to university in a capital city more than a six-hour hours drive away. While she supports her daughter "trying to put herself through school" she says that "it's really sad to see her not come home". For students who value their rural lifestyle, moving away for education can be a difficult decision to make while it is often taken for granted by those who have higher education opportunities at their doorstep. For families like Darma's, the dispersal of family is an emotional reality they must navigate in the pursuit of "living well". However, when there are viable opportunities within a community, as described by our student participants, there are alternatives to the urban (doxic) ideal expressed by Darma that alleviate the need to move away.

The juxtaposition between the hegemonic ideal of pursuing higher education and emotional and material realities of life in Oldfields highlights precisely how the widening participation agenda encourages idealism but fails to acknowledge the conditions that make some people's choice to 'stay' more viable. Young people's deep connection to their rural home in Oldfields provides an important sense of identity, social connection, and commitment to a locality of a kind that is widely ignored or

\footnotetext{
3 'Odessa' is a pseudonym.

4 'Railton' is a pseudonym.
} 
simply not valued (Howley, 2006) in the generalised policy push for increased representation of rural and remote students in higher education.

\section{Tomatillo: extreme rural decline, aspirations elsewhere}

Tomatillo is a remote community with a population of roughly 4000, of whom approximately $30 \%$ are Indigenous. The main industries are agriculture, forestry, and fishing. We interviewed six students, seven parents/carers, and two teachers at the local co-educational school, Tomatillo High School (THS). There are just over 200 students enrolled at THS, with nearly three-quarters Indigenous enrolment. Crime and unemployment are high, and the interviews suggest that drug and alcohol abuse are persistent concerns in the community. Anecdotally, despite the high percentage of families on social benefits, there are also wealthier families who work in the limited employment landscape.

Farms are the main source of employment, but work tends to be seasonal and can be affected by drought. Industry has been impacted by shifts in government funding, a common story in parts of regional and remote Australia. One parent, Romy, describes how the town has lost professionals such as dieticians, speech pathologists, occupational therapists, and podiatrists. These changes have further narrowed the range of local employment opportunities. In general, participants describe an atmosphere of dejection in the community. Another parent describes the chronic decline in basic services over the years, saying that their "little town is dying by degrees" with shops closing and very few jobs available for young people. This reality is both material and emotional for the students we interviewed, who expressed a strong impetus to leave, with little or no connection to the place in which they live.

Not surprisingly, THS experiences high teacher turnover, out-of-field teaching, and highly limited subject selection, especially in Years 11 and 12, all of which are recognised as having significant negative impacts on educational advantage and educational outcomes (Alloway \& Dalley-Trim, 2009; Cuervo, 2014; Roberts, 2015). Collectively, these realities have a detrimental impact on the culture of the school:

The culture of the school needs to change. ...There's no celebration of learning. ...The kids aren't that difficult, it's just that the systems aren't in place. ... [but] there are some kids that are really passionate [about learning]. (Brenda, teacher)

For most, a cycle of low expectations is perpetuated because, as Brenda highlights, "the systems aren't in place". Notably, Brenda places no blame on individual students but, in her critique of institutional practices, demonstrates the kind of social/spatial sensitivity (Corbett \& Forsey, 2017) that is largely absent from widening participation discourse. She recognises the need for a more positive learning culture within the school to enhance students' self-perception (Rubie-Davies, 2006). Research has consistently shown the importance of high expectations for student success, particularly for students 'at risk' (Hinnant et al., 2009), which is relevant to many of the students at THS. 
As it stands, however, precarious employment and limited educational opportunities have contributed to an exodus out of Tomatillo for families seeking work and/or schooling:

People are moving away, they're sending [kids] away to the private schools and they're moving up the coast to get a better education, because that's where most people go to get better education for better jobs and all that in the future. (Steve, Year 10 student)

Steve repeatedly uses the word "better" as he compares Tomatillo to coastal locations. His emphasis on 'better' education leading to a 'better' future embraces doxic logic, in this case underpinned by a desire for 'better' education as a way of escaping the pervasive decline and disadvantage in Tomatillo.

Yet not all students are in a position to conceive of, or pursue, such opportunities. Parent interviews depict a place where aspirations are constrained for students from certain circumstances, imposing a habituated logic on how they can imagine their futures:

There are lots of kids in Tomatillo who probably don't have a parent or a relative or anyone that has been to university, but they still have great potential and would love to go. There's no one there sort of showing them the steps on this is what you have to do to get in there. It'd be great to see more contact with universities so that it becomes normal to these children that okay it is a pathway that I can choose and it's not just the ones who have a parent that went to university. It can be for anyone. (Margit, parent)

Some of the struggles in Tomatillo are further elaborated as Romy explains that there are many families in the area who are intergenerational welfare recipients:

I don't know where they ever get the chance to break that cycle but education, I believe, is the way to break it. I don't know how people do but because there is an awful lot of [people living on welfare] in small communities, again because of the lack of access to jobs...education's the only way out. ...It takes a lot of strength of character for those kids to break out of the cycle ...that's now a bit of a social norm. The kids will have teenage pregnancies, or they just go on the dole, they'll go bludge and it's just sad, trying to get these kids to have aspirations because they walk the streets at night because they're escaping something worse at home. (Romy, parent)

Margit and Romy paint a bleak picture of life for many of the residents of Tomatillo. Margit recognises that "lots of kids" come from families where university is completely unfamiliar. In such instances, an imposed habituated logic for aspiring traps young people in a cycle of intergenerational welfare. Romy expresses a doxic belief in education as a way to "break that cycle" but suggests that for some young people, having any educational or occupational aspirations appears almost inconceivable when they are "escaping" what they might face at home. However, Margit suggests that challenging circumstances should not prevent young people from aspiring to higher education, saying that they would "love to go" [to 
university] and have "great potential" if given the right support and opportunities. These parents recognise how limited the opportunities are in Tomatillo and the importance of the school and family in facilitating post-school transitions (Kilpatrick \& Abbott-Chapman, 2002).

In this light, Julienne, one of the teachers, also draws attention to some of the challenges facing students in Tomatillo. She explains that many students who finish Year 12 have essentially been pushed, whether or not it is the 'right thing' for them to do:

At times, it's kind of dragging those kids through when really we should be pushing them elsewhere because school isn't for them and it's wasting their time and they could be looking for a trade or they could be doing anything else. ... I don't think you need to go to uni to have a great life. I don't think uni is the be all and end all for everyone and so I think I just want them to be successful in whatever they choose to do. I just don't want them to get caught up in the wrong path because we do have kids that come from families that might have criminal or drug backgrounds and they're kind of stuck in that cycle and I want them to break that cycle. (Julienne, teacher)

Julienne clearly recognises the particular circumstances of her students' lives and is concerned about their well-being. Unintentionally, however, she seems to impose the habituated logic that university is not "for them", evident in her references to "dragging... kids through" and "wasting their time". While Julienne hopes such students will somehow "break the cycle" and "be successful", she does not see higher education as the only pathway to success.

However, Julienne's views are strikingly discordant with those of the six students we spoke with. They not only indicate interest in university education but also speak about this pathway almost as a given:

I really want to go to university. That's a massive goal of mine. I don't know if I'll take a gap year. ... I don't know what I want to study at university, I just want to go. ... I was thinking maybe something to do with interior design or architecture, or the other end of the spectrum, maybe law or social studies. I really don't know. ... I think we all want to be well off in life and have a bit of money and get out of Tomatillo and just experience everything that we can. A lot of education and stuff isn't offered here. ... We can do distance, but we all want that university life. (Pippi, Year 11 student)

Pippi's desire to leave ("I really want to go", "I just want to go", "get out of Tomatillo") signals a strong connection to the doxic logic of education as a mechanism for self-improvement and mobility. Despite the supposed absence of a culture of learning at THS, Pippi is enthusiastic about her education and eager to experience what university has to offer. Her aspirations rise above the low expectations her school has of its students; certainly she does not fit the profile articulated by Julienne, Margit and Romy.

Other students also express a desire to go to university, albeit somewhat vaguely regarding their specific aspirations: 
I'd like to go to university. But as far as what career to do I wouldn't have a clue. ... I'd like to [come back]. But I'm not sure if I got a job with my degree that would be possible ... there might be job opportunities that are better somewhere else. (Atreyu, Year 11)

Atreyu expresses an awareness of the limited employment opportunities if he chooses to stay or return to Tomatillo, and although he is clearly interested in university ("I'd like to go"), his aspirations are tentative and unshaped. It is well understood that supportive school environments and teacher encouragement play an important role in the formation of aspirations (Fray et al., 2019; Cuervo, 2014) and Atreyu's comments indicate that he is possibly not receiving the level of support and encouragement he needs. The question of what responsibility schools should take in guiding and supporting students like Atreyu, who clearly have an interest in higher education, is raised by Julienne:

The other thing is I don't think our kids make good subject choices because, maybe, they don't have parents that are like 'if you wanna do this, you should probably study this' ...they don't really know the right subjects that they need to get into uni. ...That might be because we're so busy with the well-being side of things that we just don't really break down how important their subject choices are. (Julienne, Teacher)

Julienne's comments emphasise how the school's focus on well-being might be at the expense of providing support for students' post-school destinations. This is compounded by circumstances in which family networks and information might be insufficient (Kilpatrick \& Abbott-Chapman, 2002), further constraining some students' aspirations. Tomatillo demonstrates the uneven distribution of the 'capacity to aspire' to higher education (Appadurai, 2004; Bok, 2010) and how this pervasive issue is compounded by a culture of low expectations within the school (Behrendt et al., 2012).

The reiterated narrative in Tomatillo is that 'better' opportunities exist elsewhere. For students in a position to leave, such as Pippi, university is a 'ticket' to a world that offers more avenues to a 'better' life. But this doxic logic for aspiring is an option afforded only to those from families with valued social, cultural and/or economic capital. For students who do not want to-or cannot-leave, the reality is grim-few options for further education, a high likelihood of unemployment, and the encircling influence of drugs and crime.

\section{Discussion}

Our analysis of two rural communities disrupts two key policy assumptions: namely that regional and remote Australia can meaningfully be treated as a homogeneous category in the widening participation agenda; and, that university should be the only desirable and relevant goal for all young people living in regional and remote communities. The post-school pathways students ultimately choose might not align 
with policy notions of the 'ideal' but may well be ideal for those individuals in particular rural and remote contexts. It is crucial that policy looks beyond valorising the [doxic] urban ideal to ensure that young people's decision to stay or return is not undermined or seen as deficient (Cook \& Cuervo, 2020). Our analysis highlights the uneven distribution of the 'capacity to aspire' to higher education (Appadurai, 2004; Bok, 2010), and how, in some instances, a habituated logic is imposed on students when options are constrained.

Specifically, students in Oldfields 'swing' between habituated and doxic logics as they navigate the space in which aspirations and reality meet. In Oldfields, education is highly valued by teachers, parents and students alike, despite the noted limitations. Attaining a university education is not uncommon within the community but, although some students are prepared to move away to pursue higher education, they tend to do so with the hope of returning. Others are perfectly content with the local opportunities available and show a clear preference for their rural life.

In Oldfields, the lens of doxic and habituated aspirations has illuminated the complexity that lies at the heart of aspiration formation and how young people can be pulled in different directions. This case study teases out some of the intricacies involved in decision making about the future which is in stark contrast to policy discourse which simply focuses on the end goal of increased access to higher education.

It is also important to recognise how valorisation of the urban ideal affects rural communities. As shifts in the economy result in shrinking rural populations, school enrolments decline, ultimately leading to incentives for families of school-aged children to leave, causing further community depopulation, and the cycle continues (Roberts, 2015). Tomatillo highlights how economic downturns and social shifts directly impact employment and community vitality, indeed putting a spotlight on the chronic precariousness of employment that troubles many remote Australian communities (Alston \& Kent, 2003; Corbett \& Forsey, 2017; Dalley-Trim \& Alloway, 2010).

In Tomatillo, a strong desire to leave is conveyed by most of the young people we spoke with. They are enticed to seek education and employment elsewhere because there is so little opportunity in the area, particularly in their areas of interest. Such community decline leads to an exodus of families and young people seeking a 'way out' and a 'better life' elsewhere, underpinned by the doxic logic of higher education as a way outwards and upwards. For students who are already high achieving, and whose families have the financial means, leaving appears to be a certainty. For others, leaving is seemingly inconceivable. This 'rural brain drain' tends to have devastating consequences for the communities left behind (Carr \& Kefalas, 2009; Corbett \& Forsey, 2017; Gabriel, 2002).

We acknowledge that there are likely to be other perspectives in our case study communities, including more positive outlooks and experiences, which were not conveyed by our participants in Tomatillo. For example, Indigenous perspectives are not evident, despite Tomatillo having a high Indigenous population. Nonetheless, many of the perspectives of the participants we interviewed resonated with the upward mobility aspect of doxic aspirations, manifest in young people's hopes for a better life than what is currently available. The lack of certain opportunities 
in Tomatillo drives some young people to embrace a view of success that requires escape from the realities of their life in this remote Australian community.

Collectively, what the case studies demonstrate is how diverse even two regional and remote communities are, in terms of the emotional and material realities that shape young people's aspirations. While these two cases studies juxtapose what could be viewed as 'rural contentment' versus 'rural hardship', such stark opposition does not typify regional and remote Australia. Diversity is evident both between and within communities, highlighted by our conceptual framing of the analysis through the tension between doxic and habituated aspirations. We also acknowledge that this framing could not account for the decisions of some young people, like Randall, Emil, and Heike (Oldfields), whose aspirations cannot simply be viewed as doxic or habituated.

\section{Conclusion}

We began this paper by entering the ongoing conversation about inadequate policy attention to the enormous diversity in Australia's remote and rural communities. This lack of recognition has contributed to the failure of higher education equity policy to encourage greater participation from rural students. Our case studies not only demonstrate the diversity of two communities' distinct emotional and material realities but, through the lens of doxic and habituated logics, document the multiple ways in which futures are conceived within these realities. We argue for policy that is more nuanced to the needs of each community context. In so doing, we depart from old and tired discourses about 'raising aspirations' in favour of approaches that aim to accommodate the diversity of Australia's broad regional and remote category.

It is important to recognise that many students in regional and remote communities embrace a rural lifestyle and will not necessarily choose to move away for education. Oldfields provide such an account. Re-opening and potentially expanding closed services-TAFE and public transport, in particular-would provide more equitable access to tertiary education provision that leads to viable employment in the local and surrounding areas. Proximal universities might also find ways to cater more to community needs, offering and promoting programmes that relate directly to local industries.

A 'networked regional economies' approach to policy and community development ${ }^{5}$ could open up possibilities for students interested in higher education to pursue careers in their locality while simultaneously serving to revitalise communities, particularly those experiencing challenges like Tomatillo. Expanding the

\footnotetext{
5 This approach develops local economy by providing strategic infrastructure assets aimed at supporting locally inspired 'grass roots' growth. Education can be the catalyst for encouraging regeneration and growth in regional areas. For instance, partnerships can be developed between regional economic development authorities and schools and universities to "promote regional and local economic futures projects focused on building local skills that leverage regional economic advantages to better create economic development, industry expansion, regional branding and employment and population growth" (NCSEHE, 2017, p. 16).
} 
number of Regional University Centres (formerly known as Regional Study Hubs) to include more locations - currently only 24 across Australia-would be a valuable step. These facilities enable local individuals to study any tertiary courses offered by distance in Australian institutions and provide important administrative, academic, and student support services. This is not to overlook the critical role of schools, and teachers in particular, who are uniquely positioned to guide students in their decision making and support student aspirations through a culture of high expectations. This is particularly important in contexts where there are Indigenous students (Behrendt et al., 2012) and low-SES circumstances are prevalent (Van den Broeck et al., 2020). At the same time, it is crucial to acknowledge that teachers cannot sustain this work on their own.

Adopting a genuine social justice stance towards young people's futures and greater representation in higher education means recognising a diverse range of emotional and material realities, such as those presented in these two case studies. It means supporting aspirations that might not align with the doxic logic that higher education is the ideal pathway. It also means developing new policy initiatives and investments that move beyond narrow discourses of rurality so that young people can achieve and thrive in fulfilling their desired futures.

Acknowledgements This research is funded by the Australian Department of Education (Higher Education Participation and Partnerships Program). The authors wish to acknowledge the support provided by Julie Bowe, Matthew Harper, Tammy Hunter, Adam Lloyd, Bettina North, Brooke Rosser, and Wendy Taggart in the process of data collection.

Open Access This article is licensed under a Creative Commons Attribution 4.0 International License, which permits use, sharing, adaptation, distribution and reproduction in any medium or format, as long as you give appropriate credit to the original author(s) and the source, provide a link to the Creative Commons licence, and indicate if changes were made. The images or other third party material in this article are included in the article's Creative Commons licence, unless indicated otherwise in a credit line to the material. If material is not included in the article's Creative Commons licence and your intended use is not permitted by statutory regulation or exceeds the permitted use, you will need to obtain permission directly from the copyright holder. To view a copy of this licence, visit http://creativecommons.org/licen ses/by/4.0/.

\section{References}

Abbott-Chapman, J. (2011). Making the most of the mosaic: Facilitating post-school transitions to higher education of disadvantaged students. The Australian Educational Researcher, 38, 57-71.

Alloway, N., \& Dalley-Trim, L. (2009). 'High and dry' in rural Australia: Obstacles to student aspirations and expectations. Rural Society, 19(1), 49-59.

Alloway, N., Gilbert, P., Gilbert, R., \& Muspratt, S. (2004). Factors impacting on student aspirations and expectations in regional Australia. Evaluations and investigations programme. Commonwealth of Australia.

Alston, M., \& Kent, J. (2003). Educational access for Australia's rural young people: A case of social exclusion. Australian Journal of Education, 47 (1), 5-17.

Alston, M., \& Kent, J. (2009). Generation X-pendable: The social exclusion of rural and remote young people. Journal of Sociology, 45(1), 89-107

Appadurai, A. (2004). The capacity to aspire: Culture and the terms of recognition. In V. Rao \& M. Walton (Eds.), Culture and public action (pp. 59-84). Stanford University Press. 
Beutel, D., Adie, L., \& Hudson, S. (2011). Promoting rural and remote teacher education in Australia through the Over the Hill Project. International Journal of Learning, 18 (2), 377-388.

Burnheim, C., \& Harvey, A. (2016). Far from the studying crown? Regional and remote students in higher education. In A. Harvey, C. Burnheim, \& M. Brett (Eds.), Student equity in Australian higher education: Twenty-five years of A Fair Chance for All (pp. 143-162). Singapore: Springer

Gabriel, M. (2002). Australia's regional youth exodus. Journal of Rural Studies, 18(2), 209-212.

Gore, J., Holmes, K., Smith, M., Southgate, E., \& Albright, J. (2015). Socioeconomic status and the career aspirations of Australian school students: Testing enduring assumptions. The Australian Educational Researcher, 42, 155-177.

Gore, J., Holmes, K., Smith, M., Lyell, A., Ellis, H., \& Fray, L. (2015). Choosing university: The impact of schools and schooling. Final report to the National Centre for Student Equity in Higher Education. National Centre for Student Equity in Higher Education. https://www.ncsehe.edu.au/wp-content/uploads/2015/09/Choosing-University-The-Impact-of-Schools-and-Schooling.pdf

Gore, J., Holmes, K., Smith, M., Fray, L., McElduff, P., Weaver, N., \& Wallington, C. (2017). Unpacking the career aspirations of Australian school students: Towards an evidence base for university equity initiatives in schools. Higher Education Research and Development, 36, 1383-1400.

Fray, L., Gore, J., Harris, J., \& North, B. (2020). Key influences on aspirations for higher education of Australian school students in regional and remote locations: A scoping review of empirical research, 1991 2016. The Australian Educational Researcher, 47, 61-93.

Behrendt, L., Larkin, S., Griew, R., \& Kelly, P. (2012). Review of higher education access and outcomes for Aboriginal and Torres Strait Islander people: Final report. Canberra: Department of Education and Training. https://www.dese.gov.au/uncategorised/resources/review-higher-education-accessand-outcomes-aboriginal-and-torres-strait-islander-people

Bok, J. (2010). The capacity to aspire to higher education: 'It's like making them do a play without a script.' Critical Studies in Education, 51(2), 163-178.

Bourdieu, P. (1990). The logic of practice. Stanford University Press.

Bourdieu, P. (1992). The purpose of reflexive sociology (the Chicago workshop). In P. Bourdieu \& L. Wacquant (Eds.), An invitation to reflexive sociology (pp. 61-215). University of Chicago Press.

Bradley, D., Noonan, P., Nugent, H., \& Scales, B. (2008). Review of Australian higher education. Canberra: Department of Education, Employment and Workplace Relations, Australian Commonwealth Government. http://publications.unimelb.edu.au/docs/2008bradleysubmission.pdf

Bryant, L., \& Pini, B. (2011). Gender and rurality. Routledge.

Cardak, B., Brett, M., Bowden, M., Vecci, J., Barry, P., Bahtsevanoglou, J., \& McAllister, R. (2017). Regional student participation and migration: Analysis of factors influencing regional student participation and internal migration in Australian higher education. National Centre for Student Equity in Higher Education.

Carr, P., \& Kefalas, M. (2009). Hollowing out in the middle: The rural brain drain and what it means for America. Beacon Press.

Committee for Economic Development of Australia. (2018). How Unequal? Insights on Inequality. Australia: Committee for Economic Development. http://ceda.com.au/CEDA/media/General/ Publication/PDFs/CEDA-How-unequal-Insights-on-inequality-April-2018-FINAL_WEB.pdf

Cook, J., \& Cuervo, H. (2020). Staying, leaving and returning: Rurality and the development of reflexivity and motility. Current Sociology, 68(1), 60-76.

Corbett, M., \& Forsey, M. (2017). Rural youth out-migrations and education: Challenges to aspirations discourse in mobile modernity. Discourse: Studies in the Cultural Politics of Education, $38(3), 429-444$.

Creswell, J. W. (2013). Qualitative inquiry and research design: Choosing among five approaches. SAGE Publications.

Cuervo, H. (2014). Critical reflections on youth and equality in the rural context. Journal of Youth Studies, 17(4), 544-557.

Cuervo, H., \& Wyn, J. (2017). A longitudinal analysis of belonging: Temporal, performative and relational practices by young people in rural Australia. Young, 25(3), 219-234.

Cuervo, H., Chesters, J., \& Aberdeen, L. (2019). Post-school aspirations in regional Australia: An examination of the role of cultural and social capital. The Australian Educational Researcher, 46, 843-861.

Dalley-Trim, L., \& Alloway, N. (2010). Looking "outward and onward" in the outback: Regional Australian students' aspirations and expectations for their future as framed by dominant discourses of further education and training. The Australian Educational Researcher, 37(2), 107-125. 
Dufty-Jones, R., \& Connell, J. (2014). Rural change in Australia: Population, economy, environment. Ashgate.

Eacott, C., \& Sonn, C. (2006). Beyond education and employment: Exploring youth experiences of their communities, place attachment and reasons for migration. Rural Society, 16(2), 199-214.

Edwards, B., Gray, M., \& Hunter, B. (2018). The social and economic impacts of drought. The Australian Journal of Social Issues, 54(1), 22-31.

Farrugia, D., Smyth, J., \& Harrison, T. (2014). Rural young people in late modernity: Place, globalisation and the spatial contours of identity. Current Sociology, 62(7), 1036-1054.

Gale, T. (2015). Widening and expanding participation in Australian higher education: In the absence of sociological imagination. The Australian Educational Researcher, 42, 257-271.

Gale, T., \& Parker, S. (2015). To aspire: A systematic reflection on understanding aspirations in higher education. The Australian Educational Researcher, 42(2), 139-153.

Gray, I., \& Lawrence, G. (2001). A future for regional Australia: Escaping global misfortune. Cambridge University Press.

Guenther, J., Milgate, G., O’Beirne, P., \& Osborne, S. (2014). Aboriginal and Torres Strait Islander aspirations and expectations of schooling in very remote Australian schools [Paper presentation] 2018 AARE Conference Proceedings, Brisbane, QLD, Australia. https://www.aare.edu.au/data/ 2014_Conference/Full_papers/GUENTHER_14.pdf

Halsey, J. (2017). Independent review into regional, rural and remote education: Discussion paper. Canberra: Commonwealth of Australia. https://apo.org.au/sites/default/files/resource-files/2017-07/aponid98861.pdf

Halsey, J. (2018). Independent review into regional, rural and remote education: Final report. Canberra: Commonwealth of Australia. https:/www.dese.gov.au/quality-schools-package/resources/ independent-review-regional-rural-and-remote-education-final-report

Hinnant, J. B., O’Brien, M., \& Ghazarian, S. R. (2009). The longitudinal relations of teacher expectations to achievement in the early school years. Journal of Educational Psychology, 101(3), 662-670.

Howley, C. (2006). Remote possibilities: Rural children's educational aspirations. Peabody Journal of Education, 81(2), 62-80.

Howley, C., \& Howley, A. (2014). Making sense of rural education research: art, transgression, and other acts of terroir. In S. White \& M. Corbett (Eds.), Doing educational research in rural settings: Methodological issues, international perspectives and practical solutions (pp. 33-72). Taylor \& Francis.

Huijsmans, R., Ambarwati, A., Chazali, C., \& Vijayabaskar, M. (2021). Farming, gender and aspirations across young people's life course: Attempting to keep things open while becoming a farmer. The European Journal of Development Research, 33, 71-88. https://doi.org/10.1057/ s41287-020-00302-y

Kilpatrick, S., \& Abbott-Chapman, J. (2002). Rural young people's work/study priorities and aspirations: The influence of social capital. The Australian Educational Researcher, 29(1), 43-67.

Kilpatrick, S., Katersky Barnes, R., Heath, J., Lovat, A., Kong, W.-C., \& Avitatia, S. (2019). Disruptions and bridges in rural Australia: Higher education aspiration to expectation of participation. Higher Education Research and Development, 38(3), 550-564.

National Centre for Student Equity in Higher Education. (2017). Successful outcomes for regional and remote students in Australian higher education: Issues, challenges, opportunities and recommendations from research funded by the National Centre for Student Equity in Higher Education. Curtin University.

Norton, A., Cherastidthan, I., \& Mackey, W. (2018). Mapping Australian higher education 2018. Grattan Institute.

Nygård, O. (2017). Early tracking and immigrant optimism: A comparative study of educational aspirations among students in disadvantaged schools in Sweden and the Netherlands. Comparative Migration Studies, 5(1), 1-18.

Pini, B., \& Mayes, R. (2015). Australian rural education research: A geographical perspective. Australian and International Journal of Rural Education, 25(3), 26-35.

Pini, B., \& Mills, M. (2015). Constructing the rural in education: The case of Outback Kids in Australia. British Journal of Sociology of Education, 36(4), 577-594.

Pini, B., Price, R., \& McDonald, P. (2010). Teachers and the emotional dimensions of class in resource affected rural Australia. British Journal of Sociology of Education, 31(1), 17-30.

Pini, B., Carrington, S., \& Adie, L. (2015). Schooling elsewhere: Rurality, inclusion and education. International Journal of Inclusive Education, 19(7), 677-684. 
Pini, B., Morris, D., \& Mayes, R. (2016). Rural youth: Mobilities, marginalities and negotiations. In K. Nairn, P. Kraftl, \& T. Skelton (Eds.), Space, place, and environment (pp. 463-480). Springer.

Reid, J., Green, B., Copper, M., Hastings, W., Lock, G., \& White, S. (2010). Regenerating rural social space? Teacher education for rural-Regional sustainability. Australian Journal of Education, 54(3), 262-276.

Rizvi, F., \& Lingard, B. (2011). Social equity and the assemblage of values in Australian higher education. Cambridge Journal of Education, 41(1), 5-22.

Roberts, P. (2014). Researching from the standpoint of the rural. In S. White \& M. Corbett (Eds.), Doing educational research in rural settings: Methodological issues, international perspectives and practical solutions (pp. 33-72). Taylor \& Francis.

Roberts, P. (2015). Education for rural Australia. In A. Hogan \& M. Young (Eds.), Rural and regional futures (pp. 129-140). Routledge.

Roberts, P., \& Green, B. (2013). Researching rural places: On social justice and rural education. Qualitative Inquiry, 19(10), 765-774.

Robinson, S. (2012). Freedom, aspiration and informed choice in rural higher education: Why they are saying 'no.' Australian and International Journal of Rural Education, 22(2), 79-95.

Rubie-Davies, C. M. (2006). Teacher expectations and student self-perceptions: Exploring relationships. Psychology in the Schools, 43(5), 537-552.

Sellar, S., Gale, T., \& Parker, S. (2011). Appreciating aspirations in Australian higher education. Cambridge Journal of Education, 41(1), 37-52.

Smith, L. (2011). Experiential 'hot' knowledge and its influence on low-SES students' capacities to aspire to higher education. Critical Studies in Education, 52(2), 165-177.

Van den Broeck, L., Demanet, J., \& Van Houtte, M. (2020). The forgotten role of teachers in students' educational aspirations. School composition effects and the buffering capacity of teachers' expectations culture. Teaching and Teacher Education, 90, 103015.

Whitty, G., \& Clements, N. (2015). Getting into Uni in England and Australia: Who do you know, what do you know, or knowing the ropes?. International Studies in Widening Participation, 2, 44-55.

Zipin, L., Sellar, S., Brennan, M., \& Gale, T. (2015). Education for futures in marginalized regions: A sociological framework for rethinking and researching aspirations. Educational Philosophy and Theory, 47(3), 227-246.

Publisher's Note Springer Nature remains neutral with regard to jurisdictional claims in published maps and institutional affiliations.

Skye Gibson is a Research Assistant at the Teachers and Teaching Research Centre, in the School of Education at the University of Newcastle. She has worked for the centre in a range of capacities, including Editorial Manager and Project Manager. Skye's background is in secondary school teaching (Visual Arts, ESL) and adult ESL. She has also worked in different capacities in the arts and art administration. Her research interests are in art education, regional and remote education, and social ecology.

Sally Patfield is a Postdoctoral Fellow in the Teachers and Teaching Research Centre at the University of Newcastle. Sally has over 15 years' experience working in various educational contexts, including as a classroom teacher in NSW public schools, in arts education, and across professional and academic roles in higher education. Sally's doctoral research investigated school students who would be the first in their families to enter higher education, which was awarded the Ray Debus Award for Doctoral Research in Education by the Australian Association for Research in Education.

Jennifer M. Gore is a Director, Teachers and Teaching Research Centre in the School of Education at the University of Newcastle. Widely published, her research centres on quality and equity, teacher development, pedagogical reform, and enhancing student outcomes. Her current agenda focuses on the impact of Quality Teaching Rounds on teachers and students and the formation of educational aspirations during schooling. Jennifer has won more than \$23.6 million in funding. 
Leanne Fray is a Senior Research Fellow at the University of Newcastle in the Teachers and Teaching Research Centre. She has extensive experience in qualitative and mixed methods research and has previously worked on research projects across such disciplines as health, education, and social science. Her research interests include improving student access and participation in higher education. 